\title{
Identification of aspartic acid-203 in human thymidine phosphorylase as an important residue for both catalysis and non-competitive inhibition by the small molecule "crystallization chaperone" 5'-O-tritylinosine (KIN59)
}

\author{
A. Bronckaers a,1, L. Aguado b,1 ${ }^{\mathrm{b}}$ A. Negri ${ }^{\mathrm{c}}$, M.-J. Camarasa ${ }^{\mathrm{b}}$, J. Balzarini $^{\mathrm{a}}$, \\ M.-J. Pérez-Pérez ${ }^{\text {b }}$,F. Gago ${ }^{c}$, S. Liekens ${ }^{a, *}$ \\ ${ }^{a}$ Rega Institute for Medical Research, K.U.Leuven, Minderbroedersstraat 10, B-3000 Leuven, Belgium \\ ${ }^{\mathrm{b}}$ Instituto de Química Médica, CSIC, 28006 Madrid, Spain

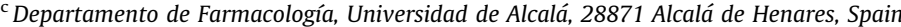

\section{A R T I C L E I N F O}

\section{Article history:}

Received 3 March 2009

Received in revised form 3 April 2009

Accepted 6 April 2009

\section{Keywords:}

Thymidine phosphorylase

5'-O-Tritylinosine (KIN59)

Allosteric inhibitor

Modeling

Mutagenesis

\begin{abstract}
A B S T R A C T
Thymidine phosphorylase (TP) is a catabolic enzyme in thymidine metabolism that is frequently upregulated in many solid tumors. Elevated TP levels are associated with tumor angiogenesis, metastasis and poor prognosis. Therefore, the use of TP inhibitors might offer a promising strategy for cancer treatment. The tritylated inosine derivative 5'-O-tritylinosine (previously designated KIN59) is a noncompetitive inhibitor of TP which was previously found to be instrumental for the crystallization of human TP. A combination of computational studies including normal mode analysis, automated ligand docking and molecular dynamics simulations were performed to define a plausible binding site for 5'-Otritylinosine on human TP. A cavity in which $5^{\prime}-O$-tritylinosine could fit was identified in the vicinity of the Gly405-Val419 loop at a distance of about $11 \AA$ from the substrate-binding site. In the X-ray crystal structure, this pocket is characterized by an intricate hydrogen-bonding network in which Asp203 was found to play an important role to afford the loop stabilization that is required for efficient enzyme catalysis. Site-directed mutagenesis of this amino acid residue afforded a mutant enzyme with a severely compromised catalytic efficiency $\left(V_{\max } / K_{\mathrm{m}}\right.$ of mutant enzyme $\sim 50$-fold lower than for wild-type TP) and pronounced resistance to the inhibitory effect of $5^{\prime}-O$-tritylinosine. In contrast, the D203A mutant enzyme kept full sensitivity to the competitive inhibitors 6-aminothymine and 6-amino-5-bromouracil, which is in line with the kinetic properties of these inhibitors. Our findings reveal the existence of a previously unrecognized site in TP that can be targeted by small molecules to inhibit the catalytic activity of TP.
\end{abstract}

(c) 2009 Elsevier Inc. All rights reserved.

\section{Introduction}

Thymidine phosphorylase (TP) is a key enzyme of the nucleoside salvage pathway [1] that catalyzes the reversible conversion of thymidine and 2 '-deoxyuridine to their respective bases and $\alpha$-D-

\footnotetext{
Abbreviations: 6A5BU, 6-amino-5-bromouracil; 6AT, 6-aminothymine; 7-DX, 7deazaxanthine; BVDU, (E)-5-(2-bromovinyl)-2'-deoxyuridine; CAM, chorio-allantoic membrane; dThd, thymidine; EDTA, ethylenediaminetetraacetic acid; KIN59, 5'-O-tritylinosine; GST, glutathione S-transferase; HPLC, high-pressure liquid chromatography; MD, molecular dynamics; MM-GBSA, molecular mechanicsgeneralized Born surface area; NMA, normal mode analysis; PMSF, phenylmethylsulfonylfluoride; RESP, restrained electrostatic potential; rmsd, root-mean-squaredeviation; SASA, solvent accessible surface area; TFT, 5-trifluorothymidine; TP, thymidine phosphorylase; TP65, 9-[8-phosphonooctyl]-7-deazaxanthine; TPI, 5chloro-6-[1-(2-iminopyrrolidinyl)methyl]uracil hydrochloride; TS, transition state.

* Corresponding author. Tel.: +32 16 337355; fax: +32 16337340 .

E-mail addresses: Annelies.bronckaers@rega.kuleuven.be (A. Bronckaers), Sandra.Liekens@rega.kuleuven.be (S. Liekens).

${ }^{1}$ Contributed equally.
}

2-deoxyribose-1-phosphate. TP not only recognizes natural $2^{\prime}$ deoxynucleosides but is also able to catalyze the phosphorolysis of several nucleoside analogues endowed with antiviral or antitumor activity, such as 5-trifluorothymidine (TFT), 5-(E)-(2-bromovinyl)2 '-deoxyuridine (BVDU) and 5-fluoro- 2 '-deoxyuridine [2-4]. In addition to its catabolic role in the nucleoside salvage pathway, TP is also implicated in tumor progression as it has been shown to stimulate angiogenesis [5-8] and protect tumor cells from apoptosis [9-11]. A wide range of tumors, including breast, colon and oesophageal carcinomas overexpress TP, and high levels of TP have been correlated with microvessel density, metastasis and poor patient survival [10].

Thus, TP represents a promising chemotherapeutic target and TP inhibitors may (i) improve the antiviral and antitumor activity of certain nucleoside analogues, and (ii) inhibit the angiogenic and anti-apoptotic activities of TP. During the last decade, several novel classes of TP inhibitors have been developed [12]. For more than 30 years, the reference TP inhibitors were 6-aminouracil derivatives 
including 6-aminothymine (6AT) and 6-amino-5-bromouracil (6A5BU) [13]. In 2000, Fukushima et al. reported on TPI (5chloro-6-[1-(2-iminopyrrolidinyl)methyl]uracil hydrochloride) as one of the most effective TP inhibitors to date, with an IC $\mathrm{I}_{50}$ value of $35 \mathrm{nM}$ [14]. In fact, a combination of TPI and TFT (designated TAS102 ) is currently being evaluated in clinical trials for the treatment of various solid tumors, including metastatic colon and breast carcinomas $[15,16]$.

Our research groups have described 7-deazaxanthine (7-DX), the first purine derivative with inhibitory activity against TP and angiogenesis in the 'chicken chorioallantoic membrane' (CAM) assay [17], and also TP65 (9-[8-phosphonooctyl]-7-deazaxanthine), the first multisubstrate inhibitor of TP that was shown to interact with both the thymidine and the phosphate binding site of TP $[18,19]$. More recently, we identified the purine nucleoside 5'-O-tritylinosine as a novel TP inhibitor $[20,21]$, in which the presence of the trityl moiety was proven to be crucial for both its inhibitory activity against TP and its anti-angiogenic effect in the CAM assay. $5^{\prime}-O-$ Tritylinosine is also a rather unique TP inhibitor because (i) it promotes the degradation of pre-existing immature vessels in the CAM assay, and (ii) in contrast to all previously described TP inhibitors, it inhibits TP in a non-competitive fashion with respect to both thymidine and phosphate. This latter finding implies that $5^{\prime}-O-$ tritylinosine does not bind to the substrate-binding sites of TP, but rather interacts with a novel, yet unknown, allosteric site of TP that could also play a role in the biological activities of this protein.

It may be mentioned that diffraction-grade crystals of human TP in complex with TPI [22] were only obtained after limited treatment with trypsin, yielding two protein fragments consisting of residues $12-408$ and $411-482$. The structure was solved at $2.7 \AA$ resolution, revealing a single protomer in the asymmetric unit, but the polypeptide stretch encompassing amino acids 407-414 could not be determined. In contrast, no proteolysis was required and well-ordered crystals with diffraction at $2.3 \AA$ resolution were obtained when both thymidine $(2 \mathrm{mM})$ and $5^{\prime}$-O-tritylinosine ( $1 \mathrm{mM})$ were present under the crystallization conditions [23]. In this latter structure, two dimers appeared in the asymmetric unit, and residues 406-415 were visible as an arginine-rich surface loop that extends across the active site cleft and appears to stabilize the closed conformation of the enzyme and the dimer interface through hydrogen bonds. Taking these two crystal structures together, it is clear that the overall fold of human TP is similar to that previously reported for $E$. coli TP $[24,25]$ and comprises a large $\alpha / \beta$ domain connected by three loops to a smaller $\alpha$ domain. These three loops act as a hinge that allows the motion of one domain relative to the other so that the enzyme can interconvert from an open, inactive form to a closed conformation that is catalytically active. Intriguingly, although the presence of $5^{\prime}$-O-tritylinosine was instrumental for yielding good-quality diffracting crystals of TP, no clear electron density was found for this non-competitive inhibitor, which in light of these findings may be regarded as a synthetic small-molecule, so-called "crystallization chaperone" [26]. For this reason, we have attempted to find a plausible binding site for $5^{\prime}$-O-tritylinosine on human TP and to provide a rationale for its behavior as a non-competitive inhibitor. Our proposal has been indirectly validated by site-directed mutagenesis of Asp-203, an amino acid that has turned out to be important not only for selective inhibition of the enzyme by the $5^{\prime}$-O-tritylinosine ligand but also for full catalytic competence of the enzyme.

\section{Methods and materials}

\subsection{Reagents}

5'-O-Tritylinosine (earlier designated KIN59) was synthesized as described previously $[20,27]$. The synthesis of 6AT and 6A5BU was performed as described [13,28]. Thymidine (dThd) and thymine (Thy) were purchased from Sigma (St-Louis, MO). The structural formulae of these compounds, as well as the reference inhibitor TPI, are depicted in Fig. 1.

\subsection{Molecular modeling}

\subsubsection{Normal mode analysis}

The X-ray crystal structure of human TP (PDB code 2JOF) [22] at 2.31 Å resolution, was retrieved from the Protein Data Bank (http:// www.rcsb.org/pdb/). To probe the flexibility of this enzyme, an elastic network model was used in which all non-hydrogen protein atoms (within a cutoff of $10 \AA$ ) were modeled as point masses and $\mathrm{C} \alpha$ atoms were connected by springs representing the interatomic force fields. Monomer A was analyzed as a large set of coupled harmonic oscillators using the normal mode analysis, deformation and refinement (NOMAD-Ref) server [29] and default parameters. The conformational changes were deduced by calculating the 10 lowest-frequency normal modes, which are those with the highest amplitudes and those most often related to large-scale structural rearrangements in proteins. Each mode was explored in its two opposite directions, thus resulting in a series of conformations different from the crystallographic structure within a maximum root-mean-square deviation (rmsd) value of $2 \AA$.

\subsubsection{Quantum mechanical methods, molecular mechanics force field and atom point charges}

The geometry of $5^{\prime}-O$-tritylinosine was first refined by means of the semi-empirical quantum mechanical program molecular orbital package (MOPAC) [30], using the AM1 Hamiltonian and PRECISE stopping criteria, and further optimized using a restricted HartreeFock (RHF) method and a 6-31G(d) basis set, as implemented in the $a b$ initio program Gaussian 03 [31]. The resulting wavefunctions were used to calculate electrostatic potential-derived (ESP) charges employing the restrained electrostatic potential (RESP) methodology, as implemented in the assisted model building with energy refinement (AMBER) suite of programs (http://amber.scripps.edu/). The missing bonded and nonbonded parameters were assigned, by analogy or through interpolation from those already present in the AMBER database, in a way consistent with the AMBER force field [32]. The geometry and atom point charges for the transition state (TS) of the phosphorolysis reaction were retrieved from previous work [33].

\subsubsection{Docking of $5^{\prime}$-O-tritylinosine into human TP}

A box encompassing both the active site and the loop regions was defined for the exploration of possible binding modes. The Lamarckian genetic algorithm implemented in AutoDock 3.0.5 [http://www.scripps.edu/pub/olson-web/doc/autodock] was then used to generate docked conformations of this inhibitor in either the original protein structure or those derived from the NMA by randomly changing the overall orientation of the molecule as well as the torsion angles of all rotatable bonds. Default settings were used except for number of runs, population size, and maximum number of energy evaluations, which were fixed at 250,100, and 250,000 , respectively. Rapid intra- and intermolecular energy evaluation of each configuration was achieved by having the receptor's atomic affinity potentials for aliphatic and aromatic carbon, oxygen, nitrogen, and hydrogen atoms precalculated in a three-dimensional grid with a spacing of $0.375 \AA$. A distancedependent dielectric function was used in the computation of electrostatic interactions.

\subsubsection{Molecular dynamics (MD) simulations}

The MD simulations were carried out using the AMBER 8.0 suite of programs [34]. A model of D203A TP was constructed using the mutagenesis module available in the molecular graphics program 
<smiles>Cc1c(N)[nH]c(=O)[nH]c1=O</smiles>

6AT<smiles>Nc1[nH]c(=O)[nH]c(=O)c1Br</smiles>

6A5BU<smiles>N=C1CCCN1Cc1[nH]c(=O)[nH]c(=O)c1Cl</smiles>

TPI<smiles>O=c1[nH]cnc2c1ncn2[C@@H]1O[C@H](COC(c2ccccc2)(c2ccccc2)c2ccccc2)[C@@H](O)[C@H]1O</smiles>

5'-O-tritylinosine (KIN59)

Fig. 1. Chemical structures of relevant TP inhibitors.

PyMOL (http://www.pymol.org/).The complexes of wild-type and D203A TP with the transition state (TS) of the reaction [33] and of wild-type TP with KIN59 were neutralized by addition of sodium ions [35] and immersed in truncated octahedrons of TIP3P water molecules [36]. Periodic boundary conditions were applied and electrostatic interactions were treated using the smooth particle mesh Ewald method [37] with a grid spacing of $1 \AA$. The cutoff distance for the non-bonded interactions was $9 \AA$. The SHAKE algorithm [38] was applied to all bonds and an integration step of 2.0 fs was used throughout. Solvent molecules and counterions were relaxed by energy minimization and allowed to redistribute around the positionally restrained solute $\left(25 \mathrm{kcal} \mathrm{mol}^{-1} \AA^{-2}\right)$ during $50 \mathrm{ps}$ of MD at constant temperature $(300 \mathrm{~K})$ and pressure ( $1 \mathrm{~atm})$. These initial harmonic restraints were gradually removed and the resulting systems were allowed to equilibrate further in the absence of any restraints for 10.0 ns during which system coordinates were collected every 2 ps for further analysis.

\subsubsection{MM-GBSA binding calculations}

The binding free energy describing protein-ligand associations is the difference between the free energy, $G$, of the complex and that of the respective binding partners, in our case the wild-type protein (TP) and the transition state of the reaction (TS), calculated over a series of snapshots $(i)$ taken from the MD trajectory

$G_{\text {bind }}=G_{(\mathrm{TP}-\mathrm{TS})}(i)-\left(G_{\mathrm{TP}}(i)+G_{\mathrm{TS}}(i)\right)$

The value of $G$ for each species was calculated using the following energy decomposition scheme, which is implemented in the molecular mechanics/generalized Born/surface area (MMGBSA) method within AMBER 8 (script mm_pbsa.pl) [39,40]:

$$
\begin{aligned}
& G=E_{\text {gas }}+G_{\text {sol }}-\text { TS } \\
& E_{\text {gas }}=E_{\text {int }}+E_{\text {ele }}+E_{\text {vdw }} \\
& E_{\text {int }}=E_{\text {bond }}+E_{\text {angle }}+E_{\text {torsion }} \\
& G_{\text {sol }}=G_{\mathrm{GB}}+G_{\text {nonpolar }} \\
& G_{\text {nonpolar }}=\gamma \text { SASA }
\end{aligned}
$$

$E_{\text {gas }}$ is the gas-phase energy, which is calculated using the AMBER force field $[41,42]$ as the sum of internal energies $\left(E_{\text {int }}\right)$, encompassing bond lengths ( $\left.E_{\text {bond }}\right)$, bond angles $\left(E_{\text {angle }}\right)$ and torsional angles ( $\left.E_{\text {torsion }}\right)$, and coulombic $\left(E_{\text {ele }}\right)$ and van der Waals $\left(E_{\mathrm{vdw}}\right)$ non-bonded energies. The solvation free energy, $G_{\mathrm{sol}}$, is decomposed into polar and nonpolar contributions: the polar contribution $\left(G_{\mathrm{GB}}\right)$ is calculated by solving the generalized Born equation [43] using dielectric constants of 1 and 78.5 for solute and solvent, respectively, whereas the nonpolar contribution, $G_{\text {nonpolar, }}$, is estimated from the solvent accessible surface area (SASA) [44], which is determined using a water probe with a radius of $1.4 \AA$. The surface tension constant $g$ was set to $0.005 \mathrm{kcal} / \mathrm{mol} / \AA^{2}$. $T$ and $S$ are the temperature and the total solute entropy, respectively. $S$ is typically estimated on the basis of classical statistical formulae and NMA of representative snapshots of energy minimized structures from a MD trajectory. In the present investigation this cumbersome procedure was obviated so that, in a first approximation, the solute entropy estimates were not included in the calculation of the free energy changes by assuming, on the basis of previous work [45], that its contribution to $\Delta G_{\text {bind }}$ would be negligible.

On the other hand, the use of a single trajectory to calculate $G_{\text {bind }}$ is conducive to a much better agreement with the experimental data than when multiple trajectories are used [46]. It is then expected that, by using a single trajectory, error cancellation will overcome the insufficient sampling of the conformational space $[45,47]$.

\subsection{Site-directed mutagenesis of human TP}

The pMOAL-10T vector containing the human TP gene (fused to glutathione S-transferase [GST]) was described and kindly provided by Prof. R. Bicknell (Oxford, UK) [48]. The mutant TP enzyme containing the D203A mutation was derived from this vector. Site-directed mutagenesis was performed using the Quick Change site-directed mutagenesis kit (Stratagene, Westburg, Leusden, The Netherlands) according to manufacturer's instructions. The oligonucleotide primers that were used are $5^{\prime} \mathrm{cgg}$ aat cct ata tgc agc cag agc tgt gac agc cac cgt gg-3' and its reverse primer (Invitrogen, Merelbeke, Belgium). After linear amplification of the plasmid using $P f u$ DNA polymerase (Stratagene) in a temperature cycler program ( $30 \mathrm{~min}$ at $95^{\circ} \mathrm{C}$ followed by 20 cycles of $30 \mathrm{~min}$ at $95^{\circ} \mathrm{C}, 1 \mathrm{~min}$ at $55^{\circ} \mathrm{C}$ and $12 \mathrm{~min}$ at $68^{\circ} \mathrm{C}$ ), wild-type (methylated) plasmid was digested with $D p n I$ restriction enzyme (Stratagene) and the mutant (unmethylated) DNA was transformed into E. coli XL1-Blue super competent cells (Stratagene). The presence of the desired mutation in the TP gene was confirmed by sequencing on an ABI Prism 3100 sequencer (Applied Biosystems, Foster City, CA), using the $A B I$ Prism Big Dye terminator cycle sequencing ready reaction kit (Applied Biosystems). 


\subsection{Purification of human recombinant TP}

The pMOAL-10T vector containing the wild-type TP or the mutant D203A TP was transfected into E. coli BL21(DE3)pLysS. Bacteria were grown overnight at $37^{\circ} \mathrm{C}$ in $2 \mathrm{YT}$ medium containing ampicillin (Bristol Myers Squibb, Brussels, Belgium) $(100 \mu \mathrm{g} / \mathrm{mL})$ and chloramphenicol (Sigma) $(100 \mu \mathrm{g} / \mathrm{mL})$, diluted $1: 10$ in fresh medium and further incubated for $5 \mathrm{~h}$ at $27^{\circ} \mathrm{C}$. Then isopropyl- $\beta$ D-thiogalactopyranoside (IPTG) (Sigma) was added to a final concentration of $0.1 \mathrm{mM}$ to induce the expression of the GST-TP fusion protein. After a further incubation for $15 \mathrm{~h}$ at $27^{\circ} \mathrm{C}$, the cells were pelleted $\left(10,000 \times \mathrm{g}\right.$ for $10 \mathrm{~min}$ at $\left.4{ }^{\circ} \mathrm{C}\right)$ and resuspended in lysis buffer (50 mM Tris, pH 7.5, $1 \mathrm{mM}$ dithiothreitol, $5 \mathrm{mM}$ EDTA, $10 \%$ glycerol, $1 \%$ Triton X-100, $0.1 \mathrm{mM}$ phenylmethylsulfonylfluoride [PMSF] and $0.15 \mathrm{mg} / \mathrm{mL}$ lysozyme). The bacterial suspensions were passed through the SLM Aminco French Pressure Cell Press (Beun de Ronde, La Abcoude, The Netherlands) and centrifuged at $20,000 \times \mathrm{g}$ for $15 \mathrm{~min}$ at $4{ }^{\circ} \mathrm{C}$. The GST-TP fusion protein was further purified from the supernatant using Glutathione Sepharose 4B (GE Healthcare, Little Chalfont, Buckinghamshire, UK), following the instructions of the manufacturer. Briefly, a 50\% glutathione-agarose slurry was added to the bacterial supernatant, incubated for $30 \mathrm{~min}$ at $4{ }^{\circ} \mathrm{C}$, and then washed three times with 10 bed volumes $(7.5 \mathrm{~mL})$ of lysis buffer without lysozyme and PMSF. Bound proteins were eluted in $50 \mathrm{mM}$ Tris $(\mathrm{pH}$ 8.0) containing $0.1 \%$ Triton $\mathrm{X}-100$ and $10 \mathrm{mM}$ glutathione. Protein content of the purified fractions was determined using Bradford reagent (Sigma, St-Louis, MO).

\subsection{TP enzyme assays}

The conversion of dThd to thymine was measured by highpressure liquid chromatography (HPLC) analysis. To determine the conversion activity, different amounts (ranging from 20 to $0.10 \mu \mathrm{g} / 500 \mu \mathrm{L}$ reaction mixture) of wild-type or mutant D203A TP were initially incubated with $100 \mu \mathrm{M}$ of dThd in TP-buffer (10 mM Tris- $\mathrm{HCl}$, pH 7.6, 1 mM EDTA, 2 mM KH $\mathrm{HOO}_{4} / \mathrm{K}_{2} \mathrm{HPO}_{4}$ and $150 \mathrm{mM} \mathrm{NaCl}$ ). At different time points (i.e. $0,15,30,60 \mathrm{~min}$ ), $100 \mu \mathrm{L}$ aliquots of the reaction mixtures were withdrawn and heated at $95{ }^{\circ} \mathrm{C}$ for $3 \mathrm{~min}$ to inactivate the enzyme. DThd was separated from thymine on a reverse-phase RP-8 column (Merck, Darmstadt, Germany) and quantified by high-pressure liquid chromatography (HPLC) analysis (Alliance 2690, Waters, Milford, MA). The separation was performed by a linear gradient from $98 \%$ buffer $\mathrm{B}\left(50 \mathrm{mM} \mathrm{NaH}_{2} \mathrm{PO}_{4}\right.$ and $5 \mathrm{mM}$ heptane sulfonic acid, $\mathrm{pH} 3.2$ ), to $20 \%$ buffer $\mathrm{B}+80 \%$ acetonitrile ( 8 min $98 \%$ buffer $\mathrm{B}+2 \%$ acetonitrile; 5 min linear gradient of $98 \%$ buffer $\mathrm{B}+2 \%$ acetonitrile to $20 \%$ buffer $\mathrm{B}+80 \%$ acetonitrile; $10 \mathrm{~min} 20 \%$ buffer $\mathrm{B}+80 \%$ acetonitrile, followed by equilibration at $98 \%$ buffer $\mathrm{B}+2 \%$ acetonitrile). Retention times of thymine and dThd were respectively 5.1 and $10.8 \mathrm{~min}$. UV-based detection was performed at $267 \mathrm{~nm}$.

In the kinetic assays, the $K_{\mathrm{m}}$ and $V_{\text {max }}$ of wild-type and mutant D203A TP were determined at varying concentrations of dThd, while the concentration of inorganic phosphate was kept constant at $25 \mathrm{mM}$. In these experiments, wild-type TP was used at a concentration of $0.5 \mu \mathrm{g} / 500 \mu \mathrm{L}$ reaction mixture in the presence of $5,3,2,1,0.5$ and $0.2 \mathrm{mM}$ dThd, while the mutant D203A TP was tested at a concentration of $10 \mu \mathrm{g} / 500 \mu \mathrm{L}$ reaction mixture in the presence of $40,30,20,15$ and $10 \mathrm{mM}$ dThd. Incubation was performed for $15 \mathrm{~min}$. At this time point, the reaction still proceeded linearly.

To evaluate the inhibitory activity of $5^{\prime}-O$-tritylinosine, 6 AT and 6 A5BU several concentrations of these TP inhibitors were added to the reaction mixtures containing $100 \mu \mathrm{M}$ (for wild-type TP) or $2.5 \mathrm{mM}$ (for mutant D203A TP) of dThd. Wild-type TP and mutant
D203A TP were used at a concentration of 0.5 and $10 \mu \mathrm{g} / 500 \mu \mathrm{L}$ reaction mixture, respectively. The mixtures were incubated for $15 \mathrm{~min}$. The amount of thymine formed was determined by HPLC analysis as described above.

\section{Results and discussion}

\subsection{Proposal of a binding mode for KIN59 on human TP}

Inspection of the Gly-405-Val-419 loop (which was clipped in the structure of Norman et al. [22]), in the crystallographic structure of El Omari et al. [23], revealed an intricate hydrogenbonding network, the most relevant part of which is schematically represented in Fig. 2: (i) the backbone NH of Arg-408 is hydrogenbonded to a well-defined water molecule (W98 in subunit A, designated WAT1) that is fixed in place by two additional hydrogen bonds: one with the backbone carbonyl of Gly-149 and another with one carboxylate oxygen from Asp-203, a residue that is situated at the terminus of $\alpha$-helix 9, (ii) the same carboxylate oxygen of Asp-203 forms a good hydrogen bond with the backbone NH of Gly-149, which is next to Leu-148, a residue whose sidechain provides a hydrophobic surface for interaction with the pyrimidine base of both the dThd substrate and competitive inhibitors such as TPI, (iii) the guanidinium group of Arg-408 establishes two strong hydrogen bonds with the carboxylate oxygens of Asp-156 (not shown) and also a water-mediated (W80 in subunit B, designated WAT2) hydrogen bond with the other Asp203 carboxylate oxygen, (iv) the carbonyl groups of the backbones of Asp-203 and Arg-408 are both accepting a hydrogen bond from a common water molecule (designated WAT3); (v) the guanidinium group of Arg-410 is partly exposed to the solvent but also engaged in an intersubunit hydrogen bond with the carbonyl group of Ser65 (not shown); and (vi) the backbone $\mathrm{CO}$ and $\mathrm{NH}$ groups of Ala411 in one protomer establish two good hydrogen bonds with the side-chain carboxamide of Gln-67 in the neighboring subunit (not shown). Thus, it appears that the Gly-405-Val-419 loop consists of closely interacting amino acids that contribute to the stabilization of the closed conformation of the enzyme (the only state that presents the integral active site) by helping to hold the $\alpha$ and $\alpha / \beta$ domains together.

When the surroundings of this loop were probed for plausible binding sites for $5^{\prime}$-O-tritylinosine using the reported X-ray crystal structure and the automated docking program AutoDock, no convincing solutions were found. $5^{\prime}-0$-Tritylinosine is a rather lipophilic compound possessing a bulky trityl moiety for which no electron density emerged in the diffraction maps. However, the molecule clearly helped stabilize the conformation of this loop in the crystal lattice [23]. We reasoned this might be due to ligand

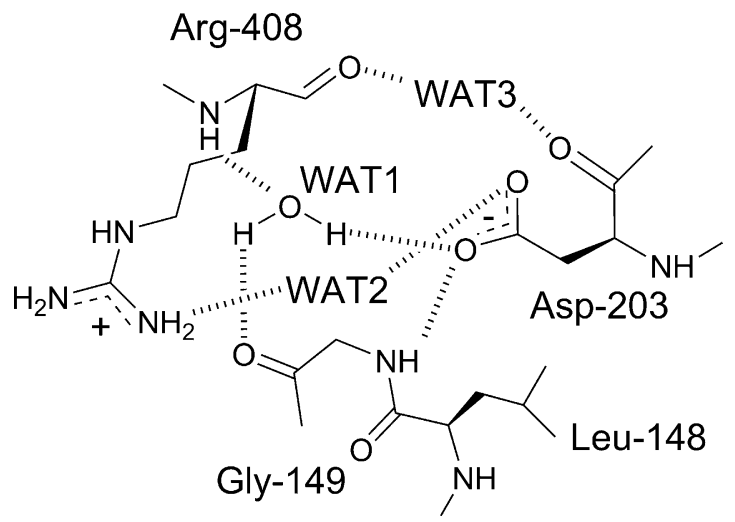

Fig. 2. Scheme depicting the most relevant hydrogen bonds that contribute to loop stabilization in the vicinity of Asp-203. For simplicity, only the atoms of one water molecule are shown. 


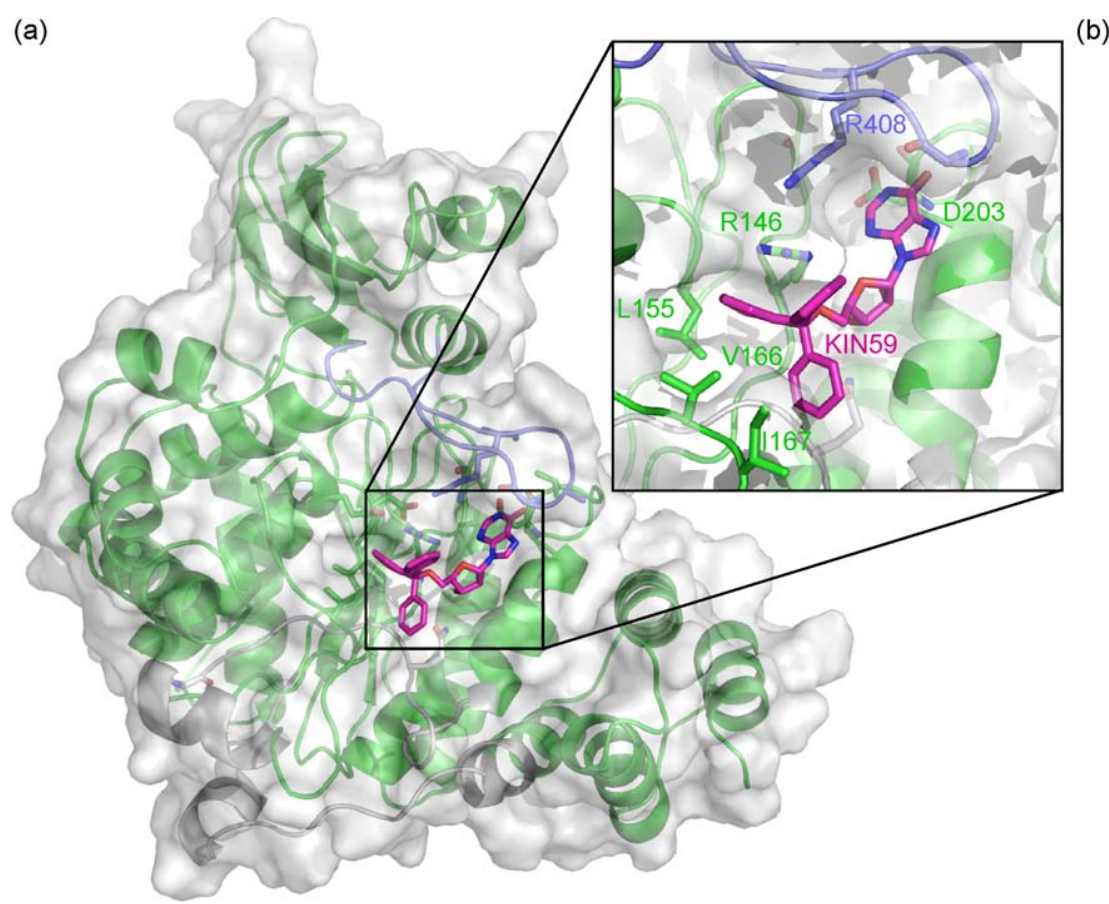

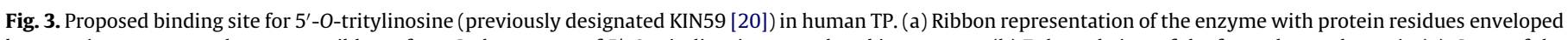

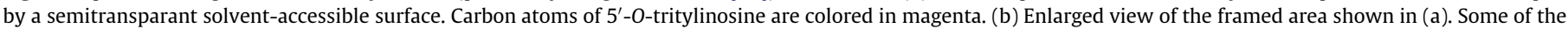
protein residues relevant to the discussion have been labeled, and their side chains are shown as sticks.

(5'-O-tritylinosine) expulsion following protein packing and local hydrophobic collapse. We therefore decided to further focus on some prior conformational state(s) of the enzyme for our docking studies. Since open and closed TP conformations are connected by hinge-dependent interdomain motions [33], as is also the case in the related pyrimidine nucleoside phosphorylase (PyNP) [49], we used normal mode analysis (NMA) to reproduce this motion and generate a series of intermediate protein conformers that could help in the identification of a region capable of lodging the hydrophobic and polar substituents of $5^{\prime}$-O-tritylinosine.

By following the lowest frequency mode, a cavity was generated in the vicinity of the Gly-405-Val-419 loop that was mainly lined by the side chains of apolar residues Leu-155, Val-166 and Ile-167, and positively charged residues Arg-146 and Arg-408, all of which can provide good anchoring points for the crucial trityl group of 5'-O-tritylinosine. Indeed, the automated docking program could find satisfactory docking solutions for $5^{\prime}-0-$ tritylinosine making use of this hydrophobic cavity. Thus, in the optimal solution, and following complex relaxation using molecular dynamics (MD), the guanidinium of Arg-146 is found stacking on top of one of the phenyl rings, which in turn makes van der Waals contacts with the side chains of Leu-155 and Val166 , whereas another phenyl of the trityl group interacts with the side chains of Val-166 and Ile-167. As regards the remaining part of the inosine nucleoside, the $3^{\prime}$ hydroxyl of the ribose is engaged in a hydrogen bond with the carboxamide group of Gln-187 (not shown), whereas the hypoxanthine moiety gets sandwiched between the tip of the Gly-405-Val-419 loop and the C-terminus of helix 9 . In this location, the heteroaromatic ring partially sits on top of the side-chain methyl of Ala-200 (not shown), N3 is close to $\mathrm{N} \varepsilon$ of Arg-146 and N1 is oriented towards the carboxylate of Asp203 and the isopropyl of Val-204 (not shown) (Fig. 3).

This docking proposal accounts for the mechanism of noncompetitive inhibition, insofar as $5^{\prime}$-O-tritylinosine does not make use of the dThd or phosphate binding sites, and is qualitatively consistent with the known structure-activity relationship for this class of 5'-O-tritylinosines [50]. Indeed, it is known that one of the phenyl rings in the essential trityl substituent can accept a chlorine atom at the para position leading to enhanced potency, and also that incorporation of a methylcyclopropyl or methylcyclohexyl substituent at the $\mathrm{N} 1$ position of hypoxanthine results in increased inhibitory activity. The former finding can be explained because

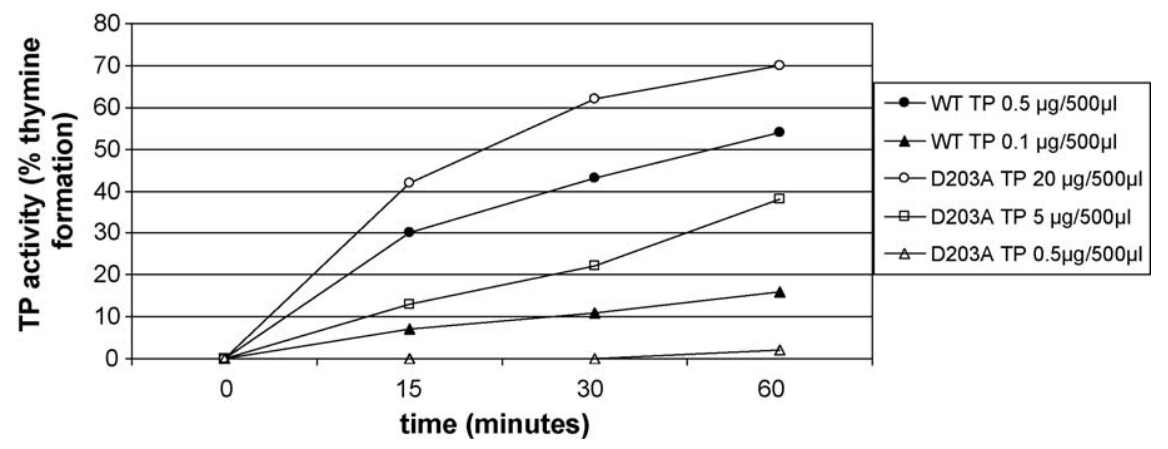

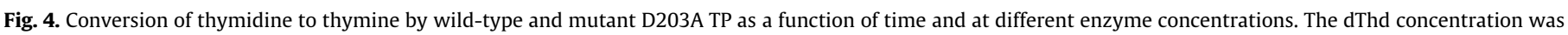
$100 \mu \mathrm{M}$. 
the chlorine atom can be held in one of the hydrophobic pockets made up by Leu-155, Val-166, and Ile-167 whereas the latter may originate from improved hydrophobic interactions between the cycloalkyl substituent and the side chain of Val-204.

Given the central role ascribed to Asp-203 in the stabilization of the Gly-405-Val-419 loop over the active-site cleft in the closed conformation, we decided to mutate this residue to alanine in order to assess the impact of this amino acid replacement on both enzyme activity and modulation of catalysis by TP inhibitors.

\subsection{Enzymatic activity and kinetic parameters of wild-type and mutant D203A TP}

The enzymatic activities of purified recombinant wild-type and mutant D203A TP were compared by using different amounts of enzyme $(0.5$ and $0.1 \mu \mathrm{g} / 500 \mu \mathrm{L}$ reaction mixture for wild-type TP and 20,5 and $0.5 \mu \mathrm{g} / 500 \mu \mathrm{L}$ reaction mixture for mutant D203A $\mathrm{TP}$ ). The enzymes were incubated for $0,15,30$ and $60 \mathrm{~min}$ in the presence of $100 \mu \mathrm{M}$ of dThd (Fig. 4). The mutant D203A TP converted markedly less substrate to thymine, as compared to the corresponding wild-type enzyme. The reaction proceeded linearly for up to at least $60 \mathrm{~min}$ at the lower TP concentrations and up to $15 \mathrm{~min}$ at the highest enzyme concentrations. Based on the enzyme concentrations used, it was estimated that the mutant D203A TP converts dThd to thymine at least 20-fold less efficiently than wild-type enzyme in the presence of $100 \mu \mathrm{M}$ dThd (Fig. 4). Thus, the mutation of aspartic acid to alanine at amino acid position 203 of TP resulted in a significant loss of efficiency to perform the phosphorolysis of dThd. Therefore, higher concentrations were used for the mutant D203A enzyme than wild-type TP to obtain reliable enzyme kinetic data that could be compared.

To determine the kinetic parameters for wild-type and mutant D203A TP the enzyme concentrations used were $0.5 \mu \mathrm{g} / 500 \mu \mathrm{L}$ reaction mixture and $10 \mu \mathrm{g} / 500 \mu \mathrm{L}$ reaction mixture, respectively. Under these experimental conditions, the enzyme-catalytic activity proceeded linearly during the incubation (15 min) time. Both enzymes were incubated in the presence of varying concentrations of dThd at a saturating concentration of inorganic phosphate. The $K_{\mathrm{m}}$ value of the mutant D203A TP $(9.8 \mathrm{mM})$ proved to be 23 times higher than that of the wild-type enzyme $\left(K_{\mathrm{m}}\right.$ : $414 \mu \mathrm{M})$, which suggests a markedly diminished affinity of the

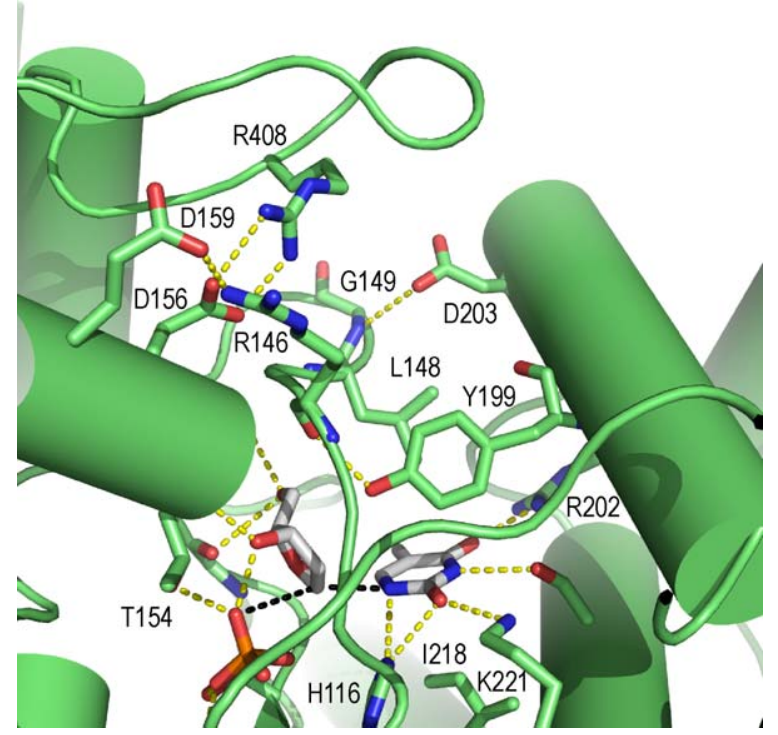

Fig. 5. Detail of the active site of wild-type TP containing the transition state of the reaction (black dashes represent bonds that are being broken/created). The most relevant residues have been labeled and hydrogen bonds are shown as yellow dashed lines.

mutant enzyme for its natural substrate dThd. Moreover, a 2.5-fold reduction in the $V_{\max }$ value $(1026 \mathrm{nmol} / \mathrm{min} / \mu \mathrm{g}$ for wild-type TP versus $400 \mathrm{nmol} / \mathrm{min} / \mu \mathrm{g}$ for mutant D203A TP) indicated that the mutation also affected (albeit to a lesser extent) the rate of dThd phosphorolysis (Table 1). Overall, the phosphorolytic capacity of the mutant D203A TP proved to be $\sim 60$-fold lower than that of wild-type TP using dThd as the natural substrate.

\subsection{Simulation of the transition state of the reaction in the wild-type and mutant D203A TP enzymes}

In light of the preceding results we sought to determine the structural basis for the decrease in catalytic performance of the mutant D203A TP relative to the wild-type enzyme using computational methods. Since the geometry of the phosphorolysis

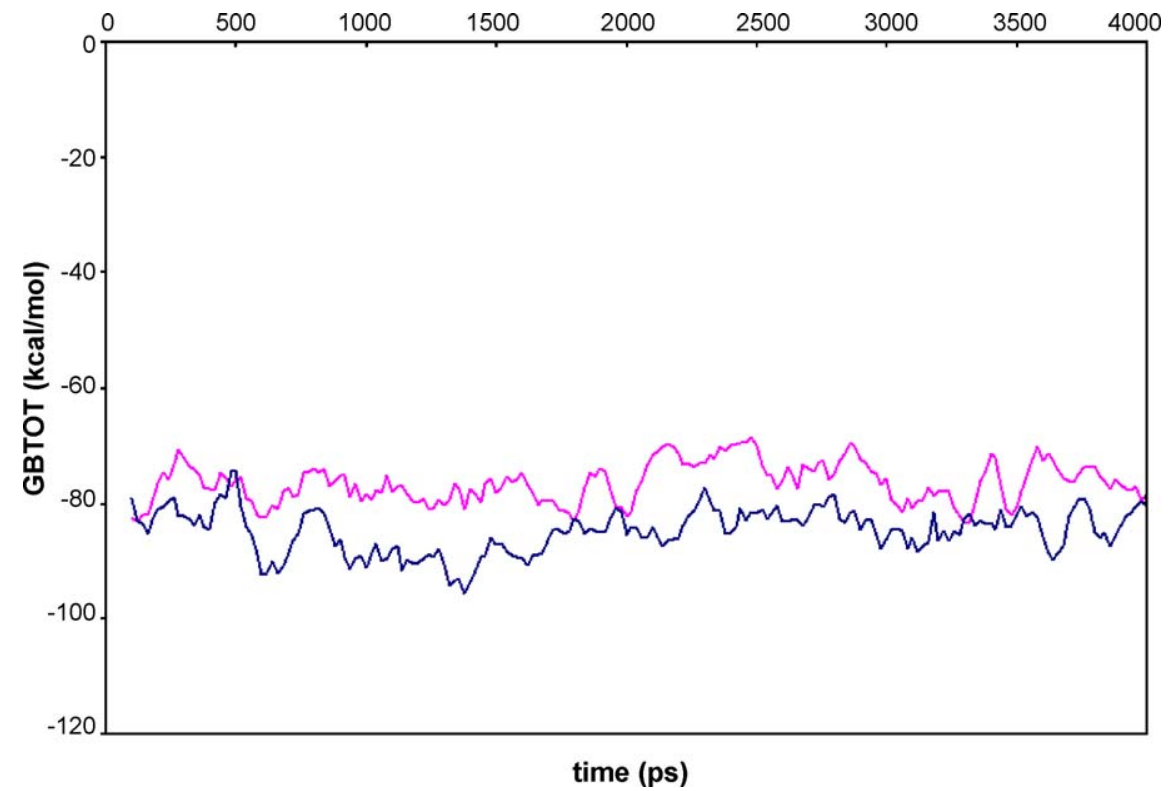

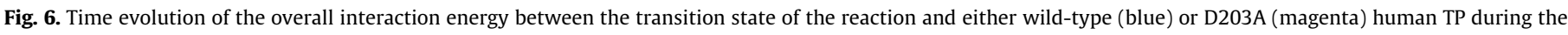
molecular dynamics simulations. 
Table 1

Kinetic parameters of human wild-type and mutant D203A TP.

\begin{tabular}{lccl}
\hline & $K_{\mathrm{m}}{ }^{\mathrm{a}}(\mu \mathrm{M})$ & $V_{\max }{ }^{\mathrm{b}}(\mu \mathrm{mol} / \mathrm{mg}$ protein $/ \mathrm{min})$ & $V_{\max } / K_{\mathrm{m}}{ }^{c}$ \\
\hline Wild-type TP & $414 \pm 96$ & $1026 \pm 460$ & 2.48 \\
D203A mutant TP & $9828 \pm 3200$ & $400 \pm 136$ & 0.041 \\
\hline
\end{tabular}

Enzyme activity is expressed as the amount of dThd converted to thymine ( $\mu \mathrm{mol} /$ $\mathrm{mg}$ protein $/ \mathrm{min}$ ). Values are presented as means \pm standard deviation of at least three independent experiments.

a $K_{\mathrm{m}}$ is the Michaelis-Menten constant of the enzyme for dThd

b $V_{\max }$ is the maximum velocity of the enzyme reaction.

c $V_{\max } / K_{\mathrm{m}}$ ratio or catalytic phosphorolytic capacity of the enzyme.

reaction transition state (TS) has been previously characterized in detail [33], unrestrained MD simulations of each enzyme in the presence of an active site-bound TS were undertaken to analyze the relative binding affinities in the two complexes.

In the wild-type enzyme the TS appears to be stabilized by a number of interactions involving both polar and apolar active-site residues (Fig. 5): (i) the pyrimidine ring gets sandwiched between the side chains of Tyr-199 and Leu-148, on one side, and that of Ile218 on the other side, and places the methyl group in the vicinity of Val-241 (not shown); (ii) the 02 and 04 of thymine accept hydrogen bonds from the amino group of Lys-221 and the guanidinium group of Arg-202, respectively, whereas the hydroxyl of Ser-217 accepts a hydrogen bond from N3 and the imidazole ring of His-116 makes a bifurcated hydrogen bond with $\mathrm{N} 1$ and $\mathrm{O} 2$; (iii) the $\mathrm{O5}^{\prime}$ of the deoxyribose accepts a H-bond from the hydroxyl of Thr-151 and donates one to the carbonyl of the backbone of Gly119 while the backbone $\mathrm{NH}$ of Thr-154 hydrogen bonds to $\mathrm{O3}^{\prime}$ of the deoxyribose, which in turn donates another $\mathrm{H}$-bond to the phosphate, precisely to the same oxygen (OP1) that accepts a second H-bond from the hydroxyl of Thr-154; and (iv) the phosphate OP3 accepts two hydrogen bonds, one from the amino group of Lys-115 and another from the hydroxyl of Ser-117 (not shown). This elaborate hydrogen-bonding pattern, which is maintained during the whole length of the MD simulation, stabilizes the TS geometry and facilitates the nucleophilic attack of the phosphate $\mathrm{O} 2 \mathrm{P}$ onto the sugar ring atom $\mathrm{C1}^{\prime}$.

By hydrogen-bonding to the NH of Gly-149, the carboxylate of Asp-203 was thus seen to play a crucial role in facilitating the correct placement of the side-chain of Leu-148. This amino acid residue has been previously shown to be essential for TP activity [7], most likely because it provides a hydrophobic platform for the stacking of both the phenol ring of Tyr-199 (which is fixed in place with the aid of a hydrogen bond from the hydroxyl group to the backbone carbonyl of Arg-146) and the pyrimidine base of the substrate and competitive inhibitors. In fact, the major difference observed within the slightly more open active site in the simulated TS-TP complex for the mutant D203A enzyme involved the positioning of Leu-148 and when the MM-GBSA method was used to calculate the binding energies of the TS within both enzymes along the simulation period, the binding energy corresponding to the mutant D203A TP was indeed found to be consistently decreased relative to the wild-type protein (Fig. 6). Moreover, the loss of binding energy originated in the van der Waals term because the electrostatic and desolvation components were virtually identical (data not shown). Therefore, even though these binding energy values have to be regarded as qualitative rather than quantitative (since entropic effects, which are cumbersome to compute and subject to large numerical errors, were not included in the calculation), the trend is very clear and is in agreement with the experimental findings: the loss of the hydrogen bond between the carboxylate of Asp-203 and the backbone $\mathrm{NH}$ of Gly-149 results in a repositioning of the side chain of Leu-148 and in a more open active site, both of which are detrimental for dThd binding, TS stabilization and efficient catalysis.

\subsection{Inhibition of wild-type and mutant D203A TP by competitive and non-competitive inhibitors}

It has been suggested that mouse liver TP contains more than one allosteric (i.e. thymine binding) site, and that when thymine is bound to one of these sites, the enzyme is inhibited [51]. We found thymine $(100 \mu \mathrm{M})$ to be inhibitory to the human TP-catalysed hydrolysis of $100 \mu \mathrm{M}$ dThd, but thymine had no effect on the inhibitory activity of $5^{\prime}$-O-tritylinosine $(200 \mu \mathrm{M}$ and $100 \mu \mathrm{M})$ (data not shown), making it unlikely that $5^{\prime}-O$-tritylinosine may bind to one of such potential thymine-binding sites.

However, we previously showed that $5^{\prime}$-O-tritylinosine inhibits $\mathrm{TP}$ in a non-competitive fashion [20]. If Asp-203 is part of a putative allosteric site to which this inhibitor binds one would expect that mutation of this amino acid residue to alanine would affect the inhibitory activity of this compound against TP. To test this hypothesis, wild-type and mutant TP enzymes were incubated for
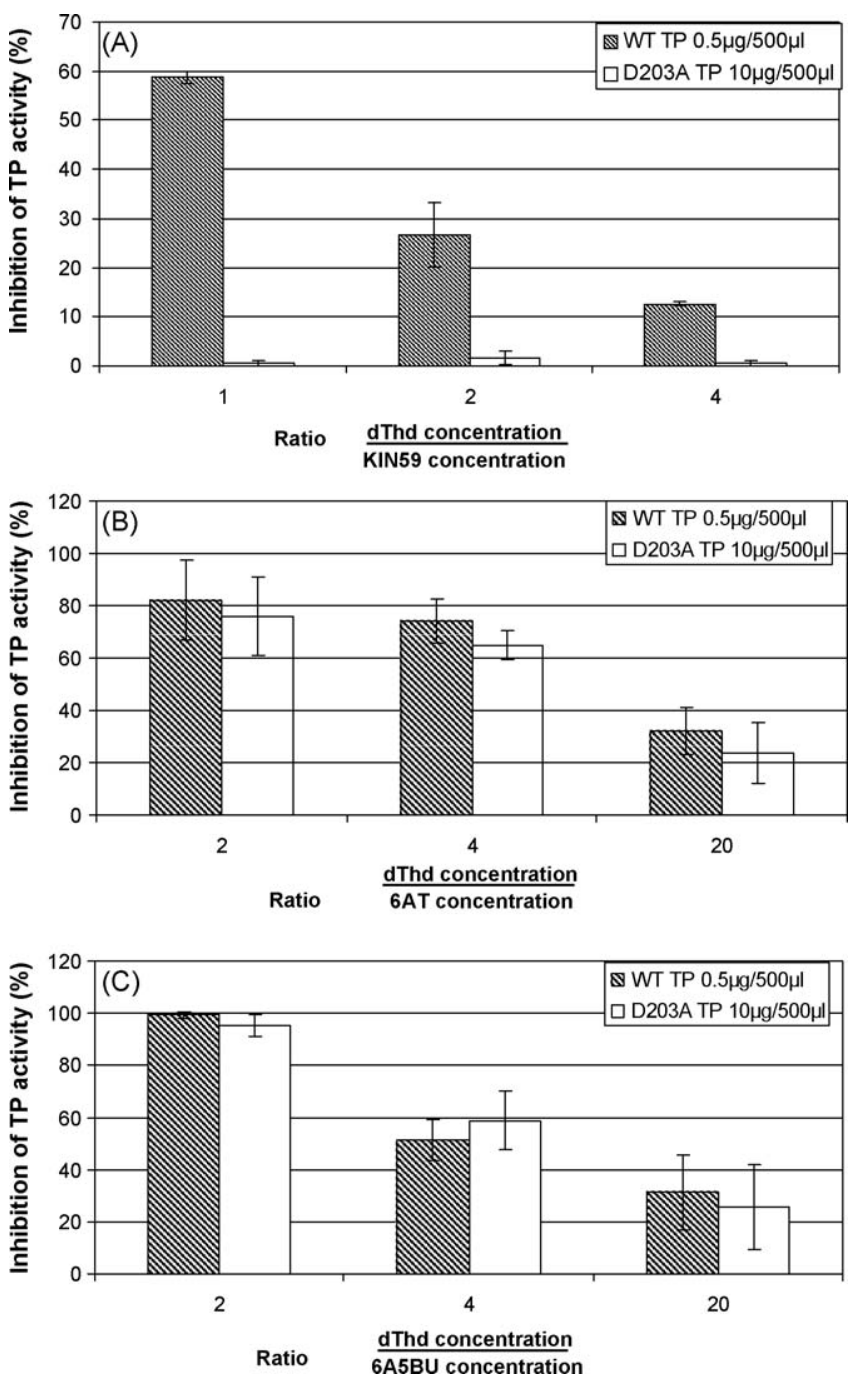

Fig. 7. Effect of the inhibitors 5'-O-tritylinosine (panel A), 6AT (panel B) and 6A5BU (panel C) on the enzymatic activity of TP. Wild-type and mutant D203A TP were incubated at $37{ }^{\circ} \mathrm{C}$ for $15 \mathrm{~min}$ at an enzyme concentration of 0.5 and $10 \mu \mathrm{g} / 500 \mu \mathrm{L}$ reaction mixture, respectively. The dThd concentration in the assays was $100 \mu \mathrm{M}$ (WT TP) or $2500 \mu \mathrm{M}$ (mutant D203A TP) to compensate for the different $K_{\mathrm{m}}$ values of both enzymes. The conversion of dThd to thymine in the presence of different amounts of inhibitors was determined by HPLC analysis. Values are presented as the mean of at least three different independent experiments \pm standard error. 
15 min with $100 \mu \mathrm{M}$ dThd in the presence of various concentrations of either the non-competitive inhibitor $5^{\prime}$-O-tritylinosine or the known competitive inhibitors 6AT and 6A5BU. As shown in Fig. 7, 5'-O-tritylinosine was completely unable to inhibit the enzymatic activity of the D203A mutant TP regardless of the concentrations used $(100,50$ and $25 \mu \mathrm{M})$ whereas a concentration-dependent inhibition of the wild-type enzyme was observed (Fig. 7, panel A). In sharp contrast, the competitive inhibitors 6AT and 6A5BU, which have been shown to interact with the dThdbinding site of TP [20], were able to dose-dependently decrease the enzymatic activity of wild-type and mutant D203A TP to a similar extent (Fig. 7, panels B and C) (6AT and 6A5BU inhibitor concentrations used: 50,25 and $5 \mu \mathrm{M}$ for wild-type TP and
1250,625 and $125 \mu \mathrm{M}$ for mutant D203A TP in the presence of $100 \mu \mathrm{M}$ dThd for wild-type TP and $2500 \mu \mathrm{M}$ dThd for mutant D203A TP). These findings are compatible with the view that binding of dThd, 6AT and 6A5BU to the active site is similarly compromised in the mutant enzyme relative to the wild-type TP whereas the putative allosteric site for $5^{\prime}-O$-tritylinosine binding is no longer present on the mutant D203A TP due to loop disruption.

\subsection{Concluding remarks}

Earlier site-directed mutagenesis studies on TP have confirmed the importance for catalysis of Lys-115, Leu-148, Arg-202, Ser-217, and Lys-221 [7,8]. All of these are active-site residues directly

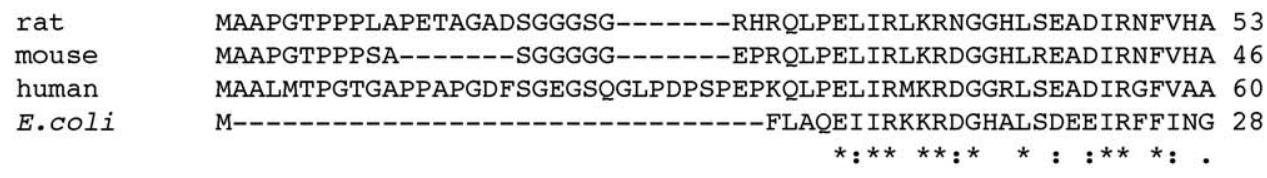

rat

mouse

human

E.Coli

rat

mouse

human

E.coli

rat

mouse

human

E.Coli

rat

mouse

human

E.coli

rat

mouse

human

E.coli

rat

mouse

human

E.Coli

rat

mouse

human

E.coli

rat

mouse

human

E.coli

LMDGRAQDTQIGAMLMAIRLQGMDLEETSVLTQALAESGQQLEWP-KAWHQQLVDKHSTG 112 VIDGRAQDTQIGAMLMAIRLQGMNLEETSVLTRALAESGQQLEWP-KAWHQQLVDKHSTG 105 VVNGSAQGAQIGAMLMAIRLRGMDLEETSVLTQALAQSGQQLEWP-EAWRQQLVDKHSTG 119 IRDNTISEGQIAALAMTIFFHDMTMPERVSLTMAMRDSGTVLDWKSLHLNGPIVDKHSTG 88 : :. . **.*: * : : : * : * ***: :** *:* . :******

GVGDKVSLVLAPALAACGCKVPMISGRSLGHTGGTLDKLESIPGFSVTQSPEQMLQILEE 172 GVGDKVSLVLAPALAACGCKVPMISGRSLGHTGGTLDKLESIPGFGVTQSPEQMLHILEE 165 GVGDKVSLVLAPALAACGCKVPMISGRGLGHTGGTLDKLESIPGFNVIQSPEQMOVLLDQ 179 GVGDVTSLMLGPMVAACGGYIPMISGRGLGHTGGTLDKLESIPGFDIFPDDNRFREIIKD 148 $\star * * * . * *: * . *: * * * * \quad: * * * * * * . * * * * * * * * * * * * * * * * * .: \quad$. : : : : : : :

VGCCIVGQSEKLVPADGILYAARDVTATVDSVPLITASILSKKAVEGLSTLVVDVKFGGA 232 VGCCIVGQSAKLVPADGILYAARDVTATVDSVPLITASILSKKAVEGLSTLVVDVKFGGA 225 AGCCIVGQSEQLVPAEGILYAARDVTATVDSLPLITASILSKKLVEGLSALVVDVKFGGA 239 VGVAIIGQTSSLAPADKRFYATRDITATVDSIPLITASILAKKLAEGLDALVMDVKVGSG 208 .*.*:**: .*.**: : ${ }^{* *}: * *: * * * * * *: * * * * * * * *: * * . * * * .: * *: * * * . * .$.

AVFPDQEKARELAKMLVRVGMGLGLQVAAALTAMDNPLGRNVGHTLEVEEALLCLDGAGP 292 AVFPDQEKARELAKMLVRVGVSLGLKVAAALTAMDNPLGRSVGHTLEVEEALLCLDGAGP 285 AVFPNQEQARELAKTLVGVGASLGLRVAAALTAMDKPLGRCVGHALEVEEALLCMDGAGP 299 *.: * * : . **: : * *. . *: : : ****:: *. .*:: :**.**: : *

-PDLRDLVIRLGGAILWLSGQAETQDQGAARVAAALDDGSALHRFQLMLSAQGVDPGLAR 351 -PDLRDLVIRLGGA ILWISGQAETQDQGAARVAAALDDGSARRRFQLMLSAQGVDPGLAK 344 -PDLRDLVTTLGGALLWLSGHAGTQAQGAARVAAALDDGSALGRFERMLAAQGVDPGLAR 358 NPRLFDVTMALCVEMLISGKLAKDDAEARAKLQAVLDNGKAAEVFGRMVAAQ-KGP---- 323

** $*$ : * : * * : : * : : *.**:.* * *::** .*

ALCSGSPTQRRQLLPHARKQEELLSPADGIVECVRALPLACVLHELGAGRSRAGQPIRPG 411 ALCSGSPTQRRQLLPHAREQEELLAPADGIVECVRALPLARVLHDLGAGRSRAGQPIRPG 404 ALCSGSPAERRQLLPRAREQEELLAPADGTVELVRALPLALVLHELGAGRSRAGEPLRLG 418 ---TDFVENYAKYLPTAMLTKAVYADTEGFVSEMDTRALGMAVVAMGGGRRQASDTIDYS 380

$$
\text { : : : : * * : : : : : *. : : .*. : : *** :*.:.: . }
$$

VGAELLVDVGQWLSRGTPWLRVHLDGPALSSQQRRTLLGALVLSDRAPFKAPSPFAELVL 471 VGAEVLVDVGQCLSRGTPWLRVHLDGPALSSQQRRTLQGALVLSDRAPFKVPSPFAELVL 464 VGAELLVDVGQRLRRGTPWLRVHRDGPALSGPQSRALQEALVLSDRAPFAAPSPFAELVL 478 VGFTDMARLGDQVDGQRPLAVIHAKDENNWQEAAKAVKAAIKLADKAPESTPTVYRR ISE 440

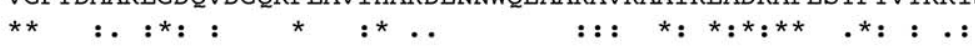

PPTTP-- 476

PPTIAQP 471

PPQQ--- 482 AFMPTYELSEALAEAIVGVANGAGVRTTALLTDMNQVLASSAGNAVEVREAVQFLTGEYR 268

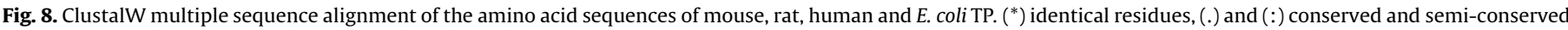

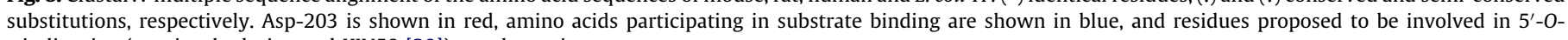
tritylinosine (previously designated KIN59 [20]) are shown in green. 
involved in the stabilization of the substrates (dThd and phosphate) and the TS, as explained above. Asp-203, on the other hand, is positioned at the end of an $\alpha$-helix and extends its side chain towards a solvent region comprised between the glycinerich 144-153 loop and the more mobile arginine-rich 406-415 loop. In this location, the Asp-203 carboxylate can accept two hydrogen bonds: one from the backbone NH of Gly-149 in the former loop (Figs. 2 and 5) and a second one from a water molecule that is, in turn, hydrogen bonded to the guanidinium of Arg-408 in the latter loop (Fig. 2). In addition, the Asp-203 carbonyl can also make a water-mediated hydrogen bond with the carbonyl of Arg408 (Fig. 2). It thus appears that Asp-203 plays a crucial role in loop stabilization, and this action is important for both catalysis and inhibition by the non-competitive inhibitor $5^{\prime}-O$-tritylinosine.

5 -O-Tritylinosine has been described previously as an inhibitor of both human and bacterial TP enzymes [20,21]. Given the noncompetitive nature of this inhibition, this purine riboside derivative was not expected to interact directly with either the pyrimidine nucleoside-binding or phosphate-binding site of the enzyme. On the contrary, this novel inhibitory mechanism was indicative of the possible existence of a yet unidentified allosteric site in the enzyme. Nonetheless, a crystal structure of human TP produced in the presence of $5^{\prime}-O$-tritylinosine revealed no traces of this inhibitor neither in the active site, which was occupied by the reaction product, thymine, nor anywhere else.

By using a combination of NMA, docking and MD simulation methods, a location for this binding site is now proposed that relies on the loop stabilization brought about by Asp-203. The sitedirected mutant D203A TP, which was constructed to assess the importance of this residue, displayed a $\sim 60$-fold reduction in phosphorolytic capacity $\left(V_{\max } / K_{\mathrm{m}}\right)$ relative to the wild-type enzyme. Importantly, both wild-type and mutant TP were inhibited to a similar extent by the competitive inhibitors 6AT and $6 \mathrm{~A} 5 \mathrm{BU}$ whereas the non-competitive inhibitor 5'-O-tritylinosine lost its inhibitory activity against the mutant D203A enzyme. These data thus support a role for Asp-203 in loop stabilization, which is important for catalytic activity, as well as for creating a rather unique binding site for 5'-O-tritylinosine. A multiple sequence alignment of human, mouse, rat and E. coli TP (Fig. 8) shows that Asp-203 is highly conserved during evolution, which reinforces the idea that this amino acid may indeed be crucial for the biological activities of TP. We previously hypothesized that this putative allosteric site might be involved in the angiogenic activity of TP $[20,21]$. Therefore, further investigations on the angiogenic and anti-apoptotic properties of the mutant D203A enzyme would be warranted.

\section{Acknowledgements}

We thank Mrs. Kristien Minner for her dedicated technical help and Mrs. Christiane Callebaut for fine editorial assistance. This research was supported by grants from the Flemish FWO [Krediet nr. G. 0486.08], the Concerted Actions [GOA nr. 05/19], the Centers of Excellence [Krediet nr. 05/15] (to J.B. and S.L.), and from Comisión Interministerial de Ciencia y Tecnología [SAF200612713-C02] and Comunidad de Madrid [S-BIO/0214/2006] (to M.J.C, M.-J.P.-P. and F.G.). Annelies Bronckaers benefits from a PhD scholarship of the FWO and Sandra Liekens is a postdoctoral fellow of the FWO. Leire Aguado thanks the Spanish Ministerio de Educación y Ciencia for a FPU predoctoral fellowship.

\section{References}

[1] Friedkin M, Roberts D. The enzymatic synthesis of nucleosides. I. Thymidine phosphorylase in mammalian tissue. J Biol Chem 1954;207:245-56.
[2] Nakayama C, Wataya Y, Meyer Jr RB, Santi DV, Saneyoshi M, Ueda T. Thymidine phosphorylase. Substrate specificity for 5-substituted 2'-deoxyuridines. J Med Chem 1980;23:962-4.

[3] Desgranges C, Razaka G, Rabaud M, Bricaud H, Balzarini J, De Clercq E. Phosphorolysis of (E)-5-(2-bromovinyl)-2'-deoxyuridine (BVDU) and other 5 -substituted-2'-deoxyuridines by purified human thymidine phosphorylase and intact blood platelets. Biochem Pharmacol 1983;32:3583-90.

[4] de Bruin M, van Capel T, Van der Born K, Kruyt FA, Fukushima M, Hoekman K, et al. Role of platelet-derived endothelial cell growth factor/thymidine phosphorylase in fluoropyrimidine sensitivity. Br J Cancer 2003;88:957-64.

[5] Haraguchi M, Miyadera K, Uemura K, Sumizawa T, Furukawa T, Yamada K, et al. Angiogenic activity of enzymes. Nature 1994;368:198.

[6] Ishikawa F, Miyazono K, Hellman U, Drexler H, Wernstedt C, Hagiwara K, et al. Identification of angiogenic activity and the cloning and expression of plateletderived endothelial cell growth factor. Nature 1989;338:557-62.

[7] Miyadera K, Sumizawa T, Haraguchi M, Yoshida H, Konstanty W, Yamada Y, et al. Role of thymidine phosphorylase activity in the angiogenic effect of platelet derived endothelial cell growth factor/thymidine phosphorylase. Cancer Res 1995;55:1687-90.

[8] Moghaddam A, Zhang HT, Fan TP, Hu DE, Lees VC, Turley H, et al. Thymidine phosphorylase is angiogenic and promotes tumor growth. Proc Natl Acad Sci USA 1995;92:998-1002.

[9] Kitazono M, Takebayashi Y, Ishitsuka K, Takao S, Tani A, Furukawa T, et al. Prevention of hypoxia-induced apoptosis by the angiogenic factor thymidine phosphorylase. Biochem Biophys Res Commun 1998;253:797-803.

[10] Liekens S, Bronckaers A, Pérez-Pérez MJ, Balzarini J. Targeting platelet-derived endothelial cell growth factor/thymidine phosphorylase for cancer therapy. Biochem Pharmacol 2007;74:1555-67.

[11] Matsushita S, Nitanda T, Furukawa T, Sumizawa T, Tani A, Nishimoto K, et al. The effect of a thymidine phosphorylase inhibitor on angiogenesis and apoptosis in tumors. Cancer Res 1999;59:1911-6.

[12] Pérez-Pérez MJ, Priego EM, Hernández AI, Camarasa MJ, Balzarini J, Liekens S. Thymidine phosphorylase inhibitors: recent developments and potential therapeutic applications. Mini Rev Med Chem 2005;5:1113-23.

[13] Langen P, Etzold G, Barwolff D, Preussel B. Inhibition of thymidine phosphorylase by 6 -aminothymine and derivatives of 6 -aminouracil. Biochem Pharmacol 1967:16:1833-7.

[14] Fukushima M, Suzuki N, Emura T, Yano S, Kazuno H, Tada Y, et al. Structure and activity of specific inhibitors of thymidine phosphorylase to potentiate the function of antitumor 2'-deoxyribonucleosides. Biochem Pharmacol 2000;59: 1227-36.

[15] Hong DS, Abbruzzese JL, Bogaard K, Lassere Y, Fukushima M, Mita A, et al. Phase I study to determine the safety and pharmacokinetics of oral administration of TAS-102 in patients with solid tumors. Cancer 2006;107:1383-90.

[16] Temmink OH, Emura T, de Bruin M, Fukushima M, Peters GJ. Therapeutic potential of the dual-targeted TAS-102 formulation in the treatment of gastrointestinal malignancies. Cancer Sci 2007;98:779-89.

[17] Balzarini J, Gamboa AE, Esnouf R, Liekens S, Neyts J, De Clercq E, et al. 7Deazaxanthine, a novel prototype inhibitor of thymidine phosphorylase. FEBS Lett 1998;438:91-5.

[18] Balzarini J, Degreve B, Esteban-Gamboa A, Esnouf R, De Clercq E, Engelborghs $\mathrm{Y}$, et al. Kinetic analysis of novel multisubstrate analogue inhibitors of thymidine phosphorylase. FEBS Lett 2000;483:181-5.

[19] Liekens S, Bilsen F, De Clercq E, Priego EM, Camarasa MJ, Pérez-Pérez MJ, et al. Anti-angiogenic activity of a novel multi-substrate analogue inhibitor of thymidine phosphorylase. FEBS Lett 2002;510:83-8.

[20] Liekens S, Hernández AI, Ribatti D, De Clercq E, Camarasa MJ, Pérez-Pérez MJ, et al. The nucleoside derivative 5'-O-trityl-inosine (KIN59) suppresses thymidine phosphorylase-triggered angiogenesis via a noncompetitive mechanism of action. J Biol Chem 2004;279:29598-605.

[21] Liekens S, Bronckaers A, Hernández AI, Priego EM, Casanova E, Camarasa MJ, et al. 5'-O-tritylated nucleoside derivatives: inhibition of thymidine phosphorylase and angiogenesis. Mol Pharmacol 2006;70:501-9.

[22] Norman RA, Barry ST, Bate M, Breed J, Colls JG, Ernill RJ, et al. Crystal structure of human thymidine phosphorylase in complex with a small molecule inhibitor. Structure 2004;12:75-84.

[23] El Omari K, Bronckaers A, Liekens S, Pérez-Pérez MJ, Balzarini J, Stammers DK. Structural basis for non-competitive product inhibition in human thymidine phosphorylase: implications for drug design. Biochem J 2006;399:199-204.

[24] Walter MR, Cook WJ, Cole LB, Short SA, Koszalka GW, Krenitsky TA, et al. Threedimensional structure of thymidine phosphorylase from Escherichia coli at 2.8 A resolution. J Biol Chem 1990;265:14016-22.

[25] Pugmire MJ, Cook WJ, Jasanoff A, Walter MR, Ealick SE. Structural and theoretical studies suggest domain movement produces an active conformation of thymidine phosphorylase. J Mol Biol 1998;281:285-99.

[26] Kossiakoff AA, Koide S. Understanding mechanisms governing protein-protein interactions from synthetic binding interfaces. Curr Opin Struct Biol 2008;18: 499-506.

[27] Casanova E, Pérez-Pérez MJ, Kappe CO. Microwave-assisted selective 5'-Otrityl protection of inosine derivatives. Synlett 2007;1733-5.

[28] Schroeder EF. US Patent 2,731,465, January 17, 1956.; Schroeder EF. Chem Abstr 1957:51:1257

[29] Lindahl E, Azuara C, Koehl P, Delarue M. NOMAD-Ref: visulatization, deformation and refinement of macromolecular structures based on all-atom normal mode analysis. Nucleic Acids Res 2006;W52-6 [http://lorentz.immstr.pasteur.fr/nomad-ref.php]. 
[30] Stewart J. MOPAC: a semiempirical molecular-orbital program. J Comput Aided Mol Des 1990;4:1-45.

[31] Frisch MJ, Trucks GW, Schlegel HB, Scuseria GE, Robb MA, Cheeseman JR, et al. Gaussian 03, revision B 04. Wallingford, CT: Gaussian, Inc.; 2004.

[32] Cornell WD, Cieplak P, Bayly CI, Gould IR, Merz KM, Ferguson DM, et al. A second generation force-field for the simulation of proteins, nucleic-acids, and organic-molecules. J Am Chem Soc 1995;117:5179-97.

[33] Mendieta J, Martin-Santamaria S, Priego EM, Balzarini J, Camarasa MJ, PérezPérez MJ, et al. Role of histidine-85 in the catalytic mechanism of thymidine phosphorylase as assessed by targeted molecular dynamics simulations and quantum mechanical calculations. Biochemistry 2004;43:405-14.

[34] Case DA, Cheatham TE, Darden T, Gohlke H, Luo R, Merz KM, et al. The Amber biomolecular simulation programs. J Comput Chem 2005;26:1668-88.

[35] Aqvist J. Ion water interaction potentials derived from free-energy perturbation simulations. J Phys Chem 1990;94:8021-4.

[36] Jorgensen WL, Chandrasekhar J, Madura JD. Comparison of simple potential functions for simulating liquid water. J Chem Phys 1983;79:926-35.

[37] Darden TA, York D, Pedersen LG. Particle mesh Ewald: an N logN method for Ewald sums in large systems. J Chem Phys 1993;98:10089-92.

[38] Ryckaert JP, Ciccotti G, Berendsen HJC. Numerical integration of cartesian equations of motion of a system with constraints: molecular-dynamics of $\mathrm{N}$ alkanes. J Comput Phys 1977;23:327-41.

[39] Kollman PA, Massova I, Reyes C, Kuhn B, Huo S, Chong L, et al. Calculating structures and free energies of complex molecules: combining molecular mechanics and continuum models. Acc Chem Res 2000;889-97.

[40] Srinivasan J, Cheatham TE, Cieplak P, Kollman PA, Case DA. Continuum solvent studies of the stability of DNA, RNA, and phosphoramidate-DNA helices. J Am Chem Soc 1998;120:9401-9.
[41] Duan Y, Wu C, Chowdhury S, Lee MC, Xiong GM, Zhang W, et al. A point-charge force field for molecular mechanics simulations of proteins based on condensedphase quantum mechanical calculations. J Comput Chem 2003;24:1999-2012.

[42] Lee MC, Duan Y. Distinguish protein decoys by using a scoring function based on a new AMBER force field, short molecular dynamics simulations, and the generalized born solvent model. Proteins 2004;55:620-34.

[43] Onufriev A, Bashford D, Case DA. Modification of the generalized Born model suitable for macromolecules. J Phys Chem 2000;104:3712-20.

[44] Sitkoff D, Sharp KA, Honig B. Accurate calculation of hydration free-energies using macroscopic solvent models. J Phys Chem 1994;98:1978-88.

[45] Huo S, Massova I, Kollman PA. Computational alanine scanning of the 1:1 human growth hormone-receptor complex. J Comput Chem 2002;23:15-27.

[46] Moreira IS, Fernandes PA, Ramos MJ. Computational alanine scanning mutagenesis-an improved methodological approach. J Comput Chem 2007;28: 644-54.

[47] Gohlke H, Kiel C, Case DA. Insights into protein-protein binding by binding free energy calculation and free energy decomposition for the Ras-Raf and RasRaIGDS complexes. J Mol Biol 2003;330:891-913.

[48] Moghaddam A, Bicknell R. Expression of platelet-derived endothelial cell growth factor in Escherichia coli and confirmation of its thymidine phosphorylase activity. Biochemistry 1992;31:12141-6.

[49] Pugmire MJ, Ealick SE. The crystal structure of pyrimidine nucleoside phosphorylase in a closed conformation. Structure 1998;6:1467-79.

[50] Casanova E, Hernández AI, Priego EM, Liekens S, Camarasa MJ, Balzarini J, et al. 5 -O-tritylinosine and analogues as allosteric inhibitors of human thymidine phosphorylase. J Med Chem 2006;49:5562-70.

[51] Iltzsch MH, el Kouni MH, Cha S. Kinetic studies of thymidine phosphorylase from mouse liver. Biochemistry 1985;24:6799-807. 